\title{
Imex Based Analysis of Repeat Sequences in Flavivirus Genomes, Including Dengue Virus
}

Chaudhary Mashhhood Alam ${ }^{1,2}$, Asif Iqbal ${ }^{1}$, Babita Thadari ${ }^{2}$ and Safdar Ali ${ }^{*}$

${ }^{1}$ PIRO Technologies Private Limited, New Delhi-110025, India

${ }^{2}$ Department of Biomedical Sciences, SRCASW, University of Delhi, Vasundhara Enclave, New Delhi-110096, India

"Corresponding author: Safdar Ali, Assistant Professor, Department of Biomedical Sciences, SRCASW, University of Delhi, New Delhi - 110096, India, Tel: 91-11-22623503; Fax: 91-11-22623504; E-mail: safdar_mgl@live.in; alisafd@gmail.com

Received date: January 21, 2016; Accepted date: January 28, 2016; Published date: January 31, 2016

Copyright: (C) 2016 Alam CM, et al. This is an open-access article distributed under the terms of the Creative Commons Attribution License, which permits unrestricted use, distribution, and reproduction in any medium, provided the original author and source are credited.

\begin{abstract}
Simple sequence repeats (SSRs), also known as microsatellites, are 1-6 nucleotides repeat motif, present in varying number of iterations, across coding and non-coding regions of prokaryotes, eukaryotes and viruses. Present study focuses on simple sequence repeats (SSRs) in 27 Flavivirus genomes, which includes dengue virus. The comparative viral genomics in the light of SSRs would help us understand the diversity and adaptability to new hosts. A total of 1164 SSRs and 53 cSSRs were uncovered from the 27 studied genomes. Mononucleotide A was the most prevalent repeat motif with an average distribution of around 6 . This was followed by $G$ (average distribution of 2). Amongst the dinucleotides AG/GA repeat motif was the most prevalent with an average distribution of 14 across studied genomes. The Flavivirus genomes lacked two essential features responsible for genome evolution, dinucleotide repeat motif AT/TA (least represented with average distribution of $\sim 0.5$ ) and cSSR in non-coding regions, suggesting a stable genome or evolution by hitherto unexplained mechanisms. The unveiling of conserved sequences in the isolates of Dengue virus suggests a basis for biomarker development for viral diagnostics.
\end{abstract}

Keywords: Flavivirus, Simple sequence repeats; Imperfect microsatellite extraction IMEx; dMAX

\section{Abbreviations}

SSR: Simple Sequence Repeat; cSSR: Compound Simple Sequence Repeat; IMEx: Imperfect Microsatellite Extraction; RD: Relative Density; RA: Relative Abundance

\section{Introduction}

Viruses utilize almost all spectra of the living world for their survival, as in host for infection and survival. The classification and evolution of viruses have been based either on the genome features (size/type) or on their host range [1,2]. A single viral genome encodes from 2 to about a thousand proteins [3,4]. Though a complete understanding of the evolutionary mechanisms driving evolution of viruses is underway, however, transposable elements and tandemly repetitive sequences are believed to play a crucial role $[5,6]$.

Simple sequence repeats (SSRs), also known as microsatellites, are 1-6 nucleotides repeat motif, present in varying number of iterations, across coding and non-coding regions of prokaryotes, eukaryotes and viruses [7-9]. SSRs, being recombination hot spots aid in genome evolution, sometimes being the basis of diseases [10,11]. Functionally, these sequences are reported to be associated with gene regulation, transcription and protein function $[12,13]$. The incidence of SSRs may be influenced by the genome features like size and GC content [14-16]. However, this correlation is not universal, adding to the enigma of SSRs.

Present study focuses on simple sequence repeats (SSRs) in 27 Flavivirus genomes, which includes Dengue virus. Dengue is a mosquito borne viral infection found in tropical and sub-tropical regions of the world and is caused by one of the four serotypes of dengue viruses (DENV1-DENV4). An increase in infection has been seen in recent years due to many factors including urbanization and air travel. Over 2.5 billion people of the world's population are now at risk for dengue. They may be asymptomatic or may give rise to undifferentiated fever, dengue fever, dengue haemorrhagic fever (DHF), or dengue shock syndrome.

Dengue virus infection has been counted among emerging and reemerging diseases because of (1) the increasing number of patients, (2) the expansion of epidemic areas, and (3) severe clinical manifestation of dengue hemorrhagic fever (DHF)/dengue shock syndrome (DSS), which is often fatal if not properly treated In the meantime, there are no effective dengue control measures: a dengue vaccine is still under development and vector control does not provide a long-lasting effect. Early recognition and prompt initiation of appropriate treatment are vital if disease related morbidity and mortality are to be limited. Our study proposes a biomarker based on repeat sequences, which can be used as an effective mode for diagnosing different strains of Dengue virus.

\section{Materials and Methods}

\section{Genome sequences}

Complete genome sequences of 27 Flavivirus were assessed and downloaded in both GenBank and FASTA formats from NCBI and subsequently analyzed for simple and compound microsatellites. The Flaviviruses included in the study and their genome features have been summarized in Table 1. Flaviviruses have monopartite linear genome of about $10-11 \mathrm{~kb}$ length. 
Citation: Alam CM, Iqbal A, Thadari B, Ali S (2016) Imex Based Analysis of Repeat Sequences in Flavivirus Genomes, Including Dengue Virus.

Page 2 of 7

\section{Microsatellite extraction}

The search for microsatellites was performed using Imperfect microsatellite extractor (IMEx) software. The analysis was done using the 'Advance- Mode' of IMEx with parameters as reported for analysis of HIV genomes; as in Type of Repeat: perfect; Repeat Size: all; Minimum Repeat Number: 6, 3, 3, 3, 3, 3; Maximum distance allowed between any two SSRs (dMAX) is 10 [7]. Two SSRs separated by a distance of less than or equal to $10 \mathrm{bp}$ would be thus treated as compound SSR (cSSR).

\section{Statistical analysis}

Microsoft Office Excel 2007 was used to perform regression analysis to predict correlation of Genome size and GC content on different parameters of SSR and cSSR such as incidence, relative abundance and relative density. Our sample size was 27 genomes, which we used in our analysis.

\section{MATLAB based tools for SSR analysis}

IMEx has been widely used to obtain the SSRs in a genome [17-22]. However, for subsequent analysis we developed two MATLAB based tools namely Identification of Gene Location from NCBI Nucleotide
File (IGLNNF) and In-corporation of Gene Location in SSR File (IGLSF). IGLNNF was used to obtain the gene locations from Genbank directly but some manual help was needed for incorporation of gene position, because only starting and end point of polyprotein were mentioned in NCBI file for species of Flavivirus genomes whereas individual member of polyprotein were mentioned separately as misc_feature. It was further saved further into (.xlsx) format. IGLSF was used to incorporate the gene location in the SSRs file.

\section{Results and Discussion}

\section{SSR/cSSR incidence}

A total of 1164 SSRs and 53 cSSRs were uncovered from the 27studied genomes. Though Flaviviruses are known to have comparable genome sizes $(10-11 \mathrm{~kb})$, the SSR incidence per genome is varying from 27 (F12) to 67 (F21) (Figure 1 and Table 1, Supplementary file 1). These variations cannot be attributed to genome size owing to small range and further highlighted by lack of colinearity between genome size and SSR incidence. For instance, F11 with genome length of $10871 \mathrm{bp}$ has 65 SSRs as compared to F19 (10892bp) has just 37 SSRs (Table 1).

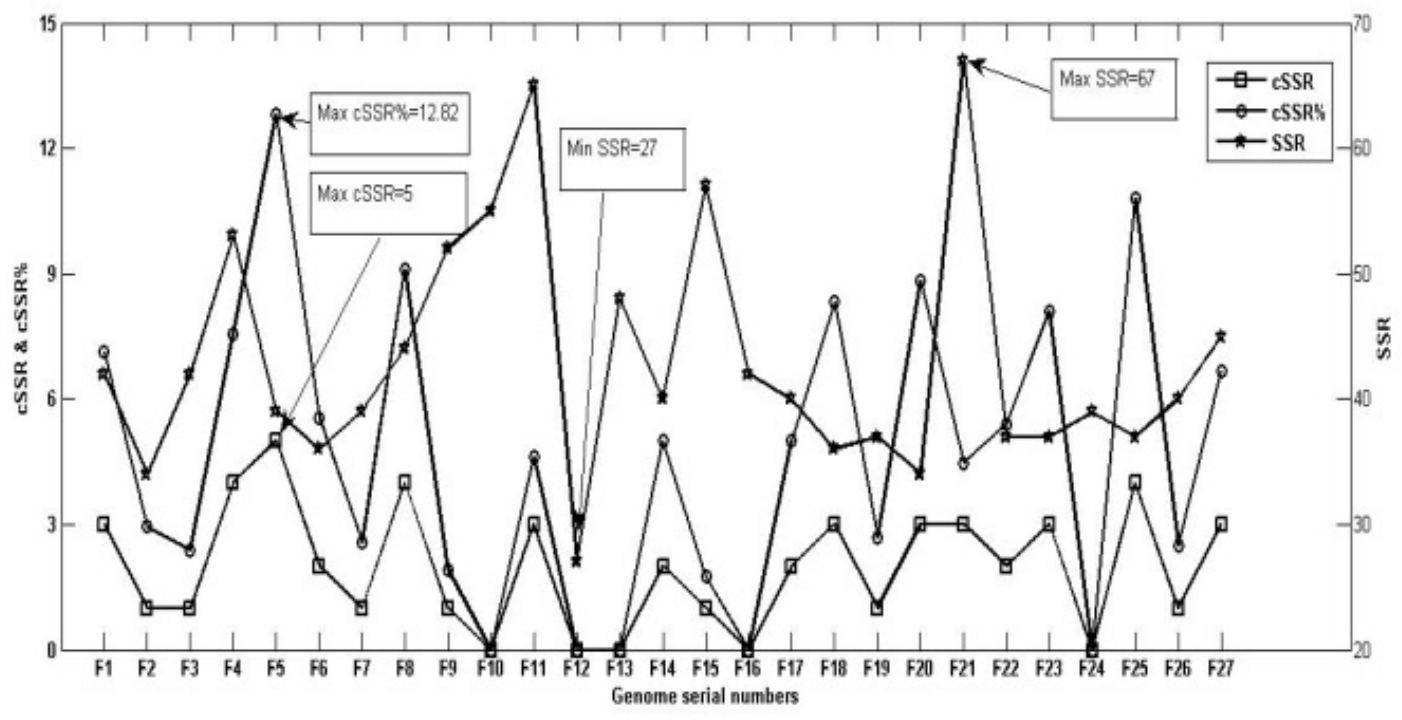

Figure 1: Incident frequency of SSRs, cSSR and cSSR\%.

\begin{tabular}{|c|c|c|c|c|c|c|c|c|c|c|c|}
\hline S.No & Genus: Flavivirus & $\begin{array}{l}\text { Accession } \\
\text { Number }\end{array}$ & GS $^{*}(\mathbf{b p})$ & $\mathrm{GC}^{* *}(\%)$ & SSRa & cSSRa & RAb & RDc & cRAb & cRDc & cSSR\%d \\
\hline $\mathrm{F} 1$ & Apoi virus & NC_003676.1 & 10116 & 48.3 & 42 & 3 & 4.15 & 23.03 & 0.30 & 4.05 & 7.14 \\
\hline $\mathrm{F} 2$ & Banzi virus & DQ859056 & 10182 & 50.4 & 34 & 1 & 3.34 & 21.70 & 0.10 & 1.18 & 2.94 \\
\hline F3 & Bouboui virus & DQ859057 & 10173 & 48.2 & 42 & 1 & 4.13 & 26.54 & 0.10 & 1.08 & 2.38 \\
\hline $\mathrm{F} 4$ & Dengue virus & AF326827 & 10618 & 47 & 53 & 4 & 4.99 & 30.80 & 0.38 & 5.46 & 7.55 \\
\hline F5 & Edge Hill virus & DQ859060 & 10206 & 47 & 39 & 5 & 3.82 & 24.99 & 0.49 & 8.72 & 12.82 \\
\hline
\end{tabular}


Citation: Alam CM, Iqbal A, Thadari B, Ali S (2016) Imex Based Analysis of Repeat Sequences in Flavivirus Genomes, Including Dengue Virus.

Page 3 of 7

\begin{tabular}{|c|c|c|c|c|c|c|c|c|c|c|c|}
\hline F6 & $\begin{array}{l}\text { Japanese encephalitis } \\
\text { virus }\end{array}$ & AF221499 & 10976 & 51.3 & 36 & 2 & 3.28 & 20.68 & 0.18 & 4.83 & 5.56 \\
\hline F7 & Jugra virus & DQ859066 & 10173 & 48.2 & 39 & 1 & 3.83 & 24.38 & 0.10 & 1.57 & 2.56 \\
\hline F8 & Kedougou virus & DQ859061 & 10227 & 53 & 44 & 4 & 4.30 & 29.53 & 0.39 & 5.87 & 9.09 \\
\hline F9 & $\begin{array}{ll}\begin{array}{l}\text { Kyasanur } \\
\text { disease virus }\end{array} & \text { Forest }\end{array}$ & HM055369 & 10774 & 55.1 & 52 & 1 & 4.83 & 31.19 & 0.09 & 1.02 & 1.92 \\
\hline F10 & Langat virus & AF253420 & 10943 & 54.3 & 55 & 0 & 5.03 & 32.99 & 0.00 & 0.00 & 0.00 \\
\hline F11 & Louping ill virus & NC_001809 & 10871 & 54.8 & 65 & 3 & 5.98 & 37.72 & 0.28 & 4.14 & 4.62 \\
\hline $\mathrm{F} 12$ & Modoc virus & AJ242984 & 10600 & 45.5 & 27 & 0 & 2.55 & 17.26 & 0.00 & 0.00 & 0.00 \\
\hline $\mathrm{F} 13$ & $\begin{array}{l}\text { Montana myotis } \\
\text { leukoencephalitis virus }\end{array}$ & AJ299445 & 10690 & 44.1 & 48 & 0 & 4.49 & 27.60 & 0.00 & 0.00 & 0.00 \\
\hline $\mathrm{F} 14$ & $\begin{array}{l}\text { Murray Valley } \\
\text { encephalitis virus }\end{array}$ & KF751871 & 10953 & 48.9 & 40 & 2 & 3.65 & 23.01 & 0.18 & 4.29 & 5.00 \\
\hline F15 & Powassan virus & NC_003687 & 10839 & 53.3 & 57 & 1 & 5.26 & 34.41 & 0.09 & 1.57 & 1.75 \\
\hline F16 & Rio Bravo virus & JQ582840 & 10742 & 43.4 & 42 & 0 & 3.91 & 24.30 & 0.00 & 0.00 & 0.00 \\
\hline F17 & Saboya virus & DQ859062 & 10173 & 47.7 & 40 & 2 & 3.93 & 24.77 & 0.20 & 2.26 & 5.00 \\
\hline F18 & Sepik virus & DQ859063 & 10218 & 47.2 & 36 & 3 & 3.52 & 24.08 & 0.29 & 4.60 & 8.33 \\
\hline F19 & $\begin{array}{l}\text { St. Louis encephalitis } \\
\text { virus }\end{array}$ & KM267635.1 & 10892 & 49.78 & 37 & 1 & 3.40 & 23.60 & 0.09 & 1.01 & 2.70 \\
\hline F20 & Tembusu virus & KR061333.1 & 10278 & 48.97 & 34 & 3 & 3.31 & 22.57 & 0.29 & 5.25 & 8.82 \\
\hline F21 & $\begin{array}{l}\text { Tick-borne encephalitis } \\
\text { virus }\end{array}$ & NC_001672 & 11141 & 53.8 & 67 & 3 & 6.01 & 42.10 & 0.27 & 3.59 & 4.48 \\
\hline $\mathrm{F} 22$ & Uganda S virus & DQ859065 & 10182 & 46.9 & 37 & 2 & 3.63 & 23.87 & 0.20 & 3.04 & 5.41 \\
\hline $\mathrm{F} 23$ & Usutu virus & AY453411 & 11066 & 51 & 37 & 3 & 3.34 & 22.77 & 0.27 & 3.98 & 8.11 \\
\hline F24 & Wesselsbron virus & JN226796 & 10814 & 47.7 & 39 & 0 & 3.61 & 23.58 & 0.00 & 0.00 & 0.00 \\
\hline $\mathrm{F} 25$ & West Nile virus & NC_009942.1 & 11029 & 51.15 & 37 & 4 & 3.35 & 22.85 & 0.36 & 5.08 & 10.81 \\
\hline F26 & Yellow fever virus & KM388815 & 10236 & 50.1 & 40 & 1 & 3.91 & 25.60 & 0.10 & 1.86 & 2.50 \\
\hline F27 & Zika virus & DQ859059 & 10254 & 50.8 & 45 & 3 & 4.39 & 29.06 & 0.29 & 3.51 & 6.67 \\
\hline
\end{tabular}

Table 1: Overview of simple and compound microsatellites in genus Flavivirus genome including dengue Virus.

Two SSRs with a distance of < dMAX between them are considered as compound SSR (cSSR). Analysis of cSSR gives an insight into the uniformity in distribution of SSRs across genomes, wherein, a colinearity between number of SSRs present and its conversion to cSSR would suggest existence of cSSR in an unbiased manner. However, the cSSR incident frequency ranged from zero to five (F5). A total of five species namely F10, F12, F13, F16 and F24 exhibited no cSSR in their genomes. These species had 55, 27, 48, 42 and 39 SSRs respectively. This variance in SSR to cSSR conversion across genomes is represented as cSSR\% which reaches a maximum of $12.82 \%$ in F5 with 39 SSRs (Figure 1 and Table 1, Supplementary file 1).

These attributes highlight two aspects about repetitive sequences. First, the distribution of SSRs is non-uniform across genomes from which we can construe their emergence and maintenance in genomes to be based on functional and regulatory implications. Secondly, the variation in cSSR\% across genomes is an outcome of differential clustering of SSRs in a genome which is suggestive of SSRs divergent roles in different genomes.

\section{Relative abundance and relative density of SSR and cSSR}

Relative abundance (RA) is number of SSRs present per $\mathrm{Kb}$ of genome while relative density (RD) is total SSR sequence per $\mathrm{Kb}$ of genome. The RA of SSR ranged from 2.55 (F12) to 6.01 (F21) and for cSSR it ranged from 0 (F10, F12, F13, F16, F24) to 0.49 (F5) (Table 1, Figure 2 and 3). The RD of SSR ranged from 17.26 (F12) to 42.10 (F21) and for cSSR it exhibited a maximum of 8.72 (F5) (Table 1, Figure 2 
and 3). The range for RA and RD across Flavivirus genomes may be considered as a representative of potential for genome evolution.

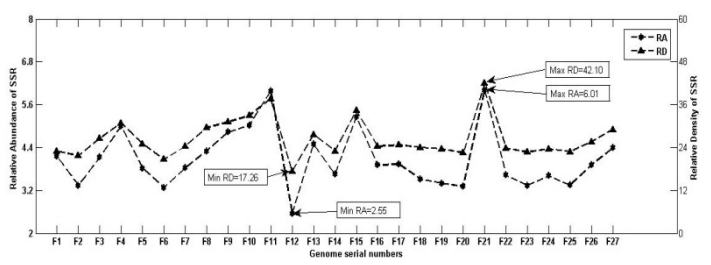

Figure 2: Relative abundance (Number of SSR per Kb of genome) and Relative density (Length occupied by SSR per Kb of genome) of SSRs.

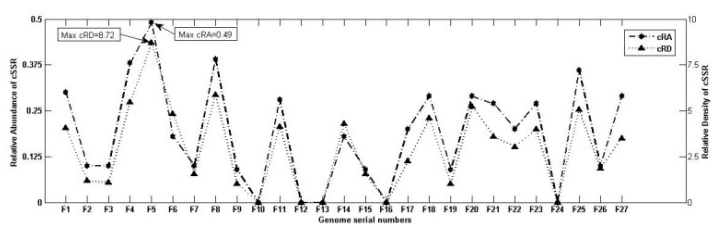

Figure 3: Relative abundance (Number of cSSR per Kb of genome) and Relative density (Length occupied by cSSR per $\mathrm{Kb}$ of genome) of cSSRs.

\section{Correlation studies}

We tested for correlation between genome size/GC content and number/relative abundance/relative density of SSRs and cSSRs. Incidence of SSRs is non-significantly correlated with genome size $\left(\mathrm{R}^{2}=0.15, \mathrm{P}>0.05\right)$ and $\mathrm{GC}$ content $\left(\mathrm{R}^{2}=0.12, \mathrm{P}>0.05\right)$. Similarly relative density $\left(\mathrm{R}^{2}=0.09, \mathrm{P}>0.05\right)$ and relative abundance $\left(\mathrm{R}^{2}=0.06, \mathrm{P}>0.05\right)$ were non- significantly correlated with genome size and GC content respectively $\mathrm{R}^{2}=0.36, \mathrm{P}>0.05$; and $\mathrm{R}^{2}=0.27, \mathrm{P}>0.05$. The regression analysis of $\operatorname{cSSR}\left(\mathrm{R}^{2}=0.02, \mathrm{P}>0.05\right)$, relative density $\left(\mathrm{R}^{2}=0.02, \mathrm{P}>0.05\right)$ and relative abundance $\left(\mathrm{R}^{2}=0.04, \mathrm{P}>0.05\right)$ shows non-significant correlation with genome size. Similarly GC content is also not significantly correlated for cSSR $\left(\mathrm{R}^{2}=0.04, \mathrm{P}>0.05\right)$, relative density $\left(\mathrm{R}^{2}=0.02, \mathrm{P}>0.05\right)$ and relative abundance $\left(\mathrm{R}^{2}=0.03, \mathrm{P}>0.05\right)$.

\section{cSSR and dMAX}

The uncovered cSSRs in present study were with a dMAX value of 10 as mentioned in section 2.2. However, IMEx has an option of varying the dMAX value between 0 and 50 [23]. So, in order to determine the impact of varying $\mathrm{dMAX}$ on cSSR incidence, five genomes F1, F7, F14, F21 and F27 were chosen at random and cSSR were extracted with increasing dMAX from 10 to 50. Expectedly, an increase in cSSRs\% with higher dMAX values were observed as represented in Figure 4. However non-linearity in the increase further corroborates our initial suggestion of unequal distribution of SSRs, as in the distances between iterations differs across genomes. The ability of motifs to induce variations is often dependent on the proximity with other motifs and hence the differences therein would lead to different genome evolution potential. The repeat sequences induce variations by strand slippage and unequal recombination, chances of which are enhanced when different SSRs are in close proximity to one another [24].

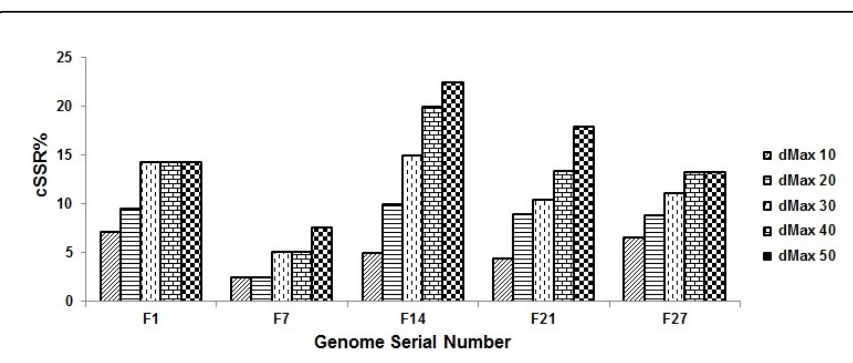

Figure 4: Frequency of cSSR-\% (Percentage of individual microsatellites being part of a compound microsatellite) in relation to varying dMAX (10 to 50 ) across 5 randomly selected genomes.

\section{Motif types in iterations}

We further looked into the divergence of repeat motifs extracted from Flavivirus genomes. The SSRs repeat motif ranged from mono- to penta-nucleotides. With the GC content in the genomes lying close to $50 \%$, a bias in the iterations was not expected. However, in mononucleotides, A was the most prevalent repeat motif with an average distribution of around 6 . This was followed by G (average distribution of 2). The least represented mononucleotide repeat motif was $\mathrm{C}$ as represented in Figure 5A. Amongst the dinucleotides AG/GA repeat motif was the most prevalent with an average distribution of 14 across studied genomes (Figure 5A). AAG/GAA was the most represented trinucleotide repeat as illustrated in Figures 5B.
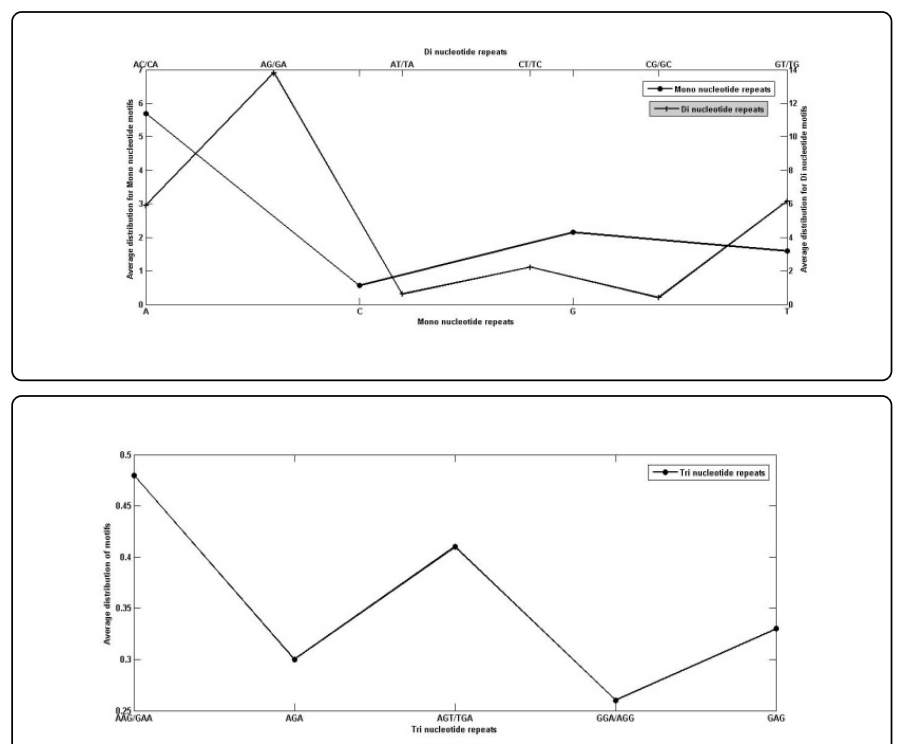

Figure 5: Average distribution of repeat motifs. 5A) Mono- or dinucleotide repeat motifs. 5B) Tri-nucleotide repeat motifs.

Further, in terms of number of iterations present at a stretch, a maximum of 49 A repeat motif were observed in F21 followed by G repeat motif of $11(\mathrm{~F} 15)$ and $10(\mathrm{~F} 21)$ respectively. Whereas in dinucleotide (AG/GA) repeat motifs maximum iteration were 5 in F10, F16 and F20. Tri-nucleotide maximum iteration repeats were found to be 4 in F1, F10, F11, F15, F21, F22 and F27 respectively. 
Citation: Alam CM, Iqbal A, Thadari B, Ali S (2016) Imex Based Analysis of Repeat Sequences in Flavivirus Genomes, Including Dengue Virus. J Data Mining Genomics Proteomics 7: 187. doi:10.4172/2153-0602.1000187

Page 5 of 7

Furthermore, the AT/TA dinucleotide motif were the least represented with average distribution of $\sim 0.5$. This motif is an established platform for SSR mutability and their low incidence is possibly suggestive of genome stability. Though repeats are known to be associated with copy number variations, strand slippage and polymorphisms accounting for genome evolution and adaptation; $[6,25,26]$ their absence can lead to converse outcomes as well.

\section{SSRs/cSSRs in coding regions}

The distribution of SSRs across coding and non-coding regions of the genomes was accomplished by first extracting the locations of genes/proposed genes in the genomes in excel format using IGLNNF. A total of $\sim 50$ proteins were thus obtained. Subsequently, this data was simulated with the SSR data through IGLSF to get the distribution across coding and non-coding regions. For our analysis, we used 11 proteins present in most number of species (Figure 6). Coding regions accounting for over $80 \%$ of the total SSRs has been observed in earlier studies [17-22] across a diverse set of viruses suggestive of their role in gene expression, regulation and evolution. In the present study, interestingly, there was no cSSR present in the non-coding region (Figure 6). This further corroborates the idea that these repeat sequences have a role to play in gene regulation and expression when present in the coding regions. And when in non-coding regions they have a role to play in introducing variations leading to genome evolution. However, the present set of genomes have a low frequency of AT/TA repeat motifs as well as cSSRs are absent in non-coding regions suggestive of relatively stable genome of Flaviviruses.

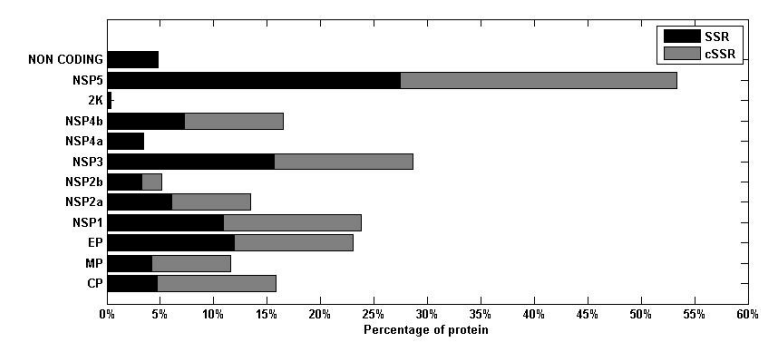

Figure 6: Differential distribution of SSRs (\%) in coding/non-coding regions of Flavivirus genomes.

\section{Conserved motifs in dengue virus}

The weak platform for genome evolution across Flavivirus genomes and the clinical significance of Dengue virus edged us to explore the possibility of conserved regions across the different isolates of Dengue viruses which can be used as biomarkers for diagnostics. The details of sequences of Dengue viruses used in the study have been listed in Table 2. These sequences were retrieved from NCBI (http:// www.ncbi.nlm.nih.-gov/) and analyzed for conserved cSSR motifs. A total of 7 motifs were subsequently analyzed and the results have been summarized in Table 3. There are 2 such motifs which were present in all the 32 studied sequences whereas another 2 motifs were represented in all but one isolate sequences. We postulate the possibility of these sequences as candidate biomarkers for a common diagnostics of different isolates of Dengue viruses.

\begin{tabular}{|l|l|l|}
\hline S. No & Dengue virus isolate & Accession No \\
\hline D1 & Dengue virus vector p4(Delta30) & AY376438.1| \\
\hline D2 & Dengue virus type 4 recombinant clone 2Adel30 & AF326826.1| \\
\hline D3 & Dengue virus type 4 vector p4 & AY648301.1| \\
\hline D4 & Dengue virus type 4 recombinant clone rDEN4 & AF326825.1| \\
\hline D5 & DENSTRA Dengue virus type 4 & M14931.2| \\
\hline D6 & Dengue virus type 4 recombinant clone 2A & AF375822.1| \\
\hline D7 & Dengue virus type 4 strain 814669 & AF326573.1| \\
\hline D8 & Dengue virus strain Dakar HD 34460 & KF907503.1| \\
\hline D9 & Dengue virus 4 strain 341750 & GU289913.1| \\
\hline
\end{tabular}


Citation: Alam CM, Iqbal A, Thadari B, Ali S (2016) Imex Based Analysis of Repeat Sequences in Flavivirus Genomes, Including Dengue Virus. J Data Mining Genomics Proteomics 7: 187. doi:10.4172/2153-0602.1000187

Page 6 of 7

\begin{tabular}{|c|c|c|}
\hline D10 & Dengue virus 4 strain $\mathrm{H} 402276$ & JN559740.2 \\
\hline D11 & Dengue virus 4 isolate DENV-4/US/BID-V2429/1994 & GQ199878.1| \\
\hline D12 & Dengue virus 4 isolate DENV-4/US/BID-V2437/1996 & GQ199883.1| \\
\hline D13 & Dengue virus 4 isolate DENV-4/US/BID-V2440/1996 & FJ850058.1| \\
\hline D14 & Dengue virus 4 isolate DENV-4/US/BID-V860/1994 & FJ226067.1| \\
\hline D15 & Dengue virus 4 isolate DENV-4/US/BID-V2438/1996 & GQ199884.1| \\
\hline D16 & Dengue virus 4 isolate DENV-4/US/BID-V2435/1996 & GQ199881.1| \\
\hline D17 & Dengue virus 4 isolate Haiti73 & JF262782.1| \\
\hline D18 & Dengue virus 4 isolate DENV-4/US/BID-V2439/1996 & GQ199885.1| \\
\hline D19 & Dengue virus 4 isolate DENV-4/US/BID-V1094/1998 & EU854297.1| \\
\hline D20 & Dengue virus 4 isolate DENV-4/US/BID-V2436/1996 & GQ199882.1| \\
\hline D21 & Dengue virus 4 isolate INH6412 & JF262781.1| \\
\hline D22 & Dengue virus 4 isolate DENV-4/VE/BID-V2163/1998 & FJ639736.1| \\
\hline D23 & Dengue virus 4 isolate DENV-4/US/BID-V2446/1999 & FJ882599.1| \\
\hline D24 & Dengue virus 4 isolate DENV-4/US/BID-V2448/1999 & FJ882601.1| \\
\hline D25 & Dengue virus 4 isolate DENV-4/VE/BID-V2172/1999 & FJ639744.1| \\
\hline D26 & Dengue virus 4 isolate DENV-4/CO/BID-V1600/1997 & FJ024476.1| \\
\hline D27 & Dengue virus 4 isolate DENV-4/VE/BID-V2607/2006 & JN819406.1 \\
\hline D28 & Dengue virus 4 strain $\mathrm{H} 780120$ & JQ513341.1| \\
\hline D29 & Dengue virus 4 strain $\mathrm{H} 772854$ & JN559741.2| \\
\hline D30 & Dengue virus 4 isolate $\mathrm{Br} 246 \mathrm{RR} / 10$ & JN983813.1 \\
\hline D31 & Dengue virus 4 strain $\mathrm{H} 779228$ & JQ513338.1| \\
\hline D32 & Dengue virus 4 strain $\mathrm{H} 772846$ & JQ513330.1] \\
\hline
\end{tabular}

Table 2: Details of Dengue virus sequences used in the study.

\begin{tabular}{|l|l|l|l|}
\hline S. No & Motif & Motif present/total sequences analyzed & Candidate Biomarker \\
\hline 1 & $(\mathrm{AG})_{3}-\mathrm{X}_{1}-(\mathrm{AG})_{3}$ & $31 / 32$ (Absent in D32) & Yes \\
\hline 2 & $(\mathrm{AG})_{3}-\mathrm{X}_{3}-(\mathrm{A})_{6}$ & $32 / 32$ & Yes \\
\hline 3 & $(\mathrm{AC})_{3}-\mathrm{X}_{4}-(\mathrm{AG})_{3}$ & $32 / 32$ & Yes \\
\hline 4 & $(\mathrm{GA})_{3}-\mathrm{X}_{6}-(\mathrm{GA})_{3}$ & $31 / 32($ Absent in D26) & Yes \\
\hline 5 & $(\mathrm{TG})_{3}-\mathrm{X}_{6}-(\mathrm{C})_{6}$ & $2 / 32$ & No \\
\hline 6 & $(\mathrm{AG})_{4}-\mathrm{X}_{2}-(\mathrm{TC})_{3}$ & $3 / 32$ & No \\
\hline 7 & $(\mathrm{AG})_{3}-\mathrm{X}_{9}-(\mathrm{A})_{6}$ & $20 / 32$ & Maybe \\
\hline
\end{tabular}

Table 3: Conserved iterations in dengue virus.

Recent studies have demonstrated that discrete steps in the replication cycles of these viruses can be inhibited by pharmacological agents that target host factors mediating lipid synthesis, metabolism, trafficking, and signal transduction. Lipids are necessary for every step in the replication cycle of Hepatitis $C$ virus $(\mathrm{HCV})$ and Dengue virus (DENV), members of the family Flaviviridae. Despite this, targeting host lipid metabolism and trafficking as an antiviral strategy by blockade of entire biosynthetic pathways may be limited due to host 
Citation: Alam CM, Iqbal A, Thadari B, Ali S (2016) Imex Based Analysis of Repeat Sequences in Flavivirus Genomes, Including Dengue Virus. J Data Mining Genomics Proteomics 7: 187. doi:10.4172/2153-0602.1000187

Page 7 of 7

toxicity therein highlighting the need for better diagnostics to counter the challenge of these viruses.

\section{Conclusion}

The comparative viral genomics in the light of SSRs would help us understand the diversity and adaptability to new hosts. The Flavivirus genomes lacked two essential features responsible for genome evolution, dinucleotide repeat motif AT/TA (least represented with average distribution of $\sim 0.5$ ) and cSSR in non-coding regions, suggesting a stable genome or evolution by hitherto unexplained mechanisms. The unveiling of conserved sequences in the isolates of Dengue virus suggests a basis for biomarker development for viral diagnostics.

\section{Acknowledgement}

We thank Department of Biomedical Sciences, Shaheed Rajguru College of Applied Sciences for Women, University of Delhi, Delhi-96, India and PIRO Technologies Private Limited, New Delhi-25, India for the financial and infrastructural support provided.

\section{References}

1. Gao L, Qi J (2007) Whole genome molecular phylogeny of large dsDNA viruses using composition vector method. BMC Evol Biol 7: 41.

2. Iyer LM, Balaji S, Koonin EV, Aravind L (2006) Evolutionary genomics of nucleo-cytoplasmic large DNA viruses. Virus Res 117: 156-184.

3. Mrázek J, Karlin S (2007) Distinctive features of large complex virus genomes and proteomes. Proc Natl Acad Sci U S A 104: 5127-5132.

4. Van Etten JL, Lane LC, Dunigan DD (2010) DNA Viruses: The Really Big Ones (Giruses). Annu Rev Microbiol 64: 83-99.

5. Bennetzen JL (2000) Transposable element contributions to plant gene and genome evolution. Plant Mol Biol 42: 251-269.

6. Hancock JM (2002) Genome size and the accumulation of simple sequence repeats: implications of new data from genome sequencing projects. Genetica 115: 93-103.

7. Chen M, Tan Z, Zeng G, Zhuotong Z (2012) Differential distribution of compound microsatellites in various Human Immunodeficiency Virus Type 1 complete genomes. Infection Genetics and Evolution 12: 14521457.

8. Gur-Arie R, Cohen CJ, Eitan Y (2000) Simple sequence repeats in Escherichia coli: abundance, distribution, composition, and polymorphism. Genome Res 10: 62-71.

9. Kofler R, Schlotterer C, Luschutzky E, Lelley T (2008) Survey of microsatellite clustering in eight fully sequenced species sheds light on the origin of compound microsatellites. BMC Genomics 9: 612 .
10. Jeffreys AJ, Holloway JK, Kauppi L, May CA, Neumann R et al (2004) Meiotic recombination hot spots and human DNA diversity. Philos Trans R Soc Lond B Biol Sci 359: 141-152.

11. Kovtun IV, McMurray CT (2008) Features of trinucleotide repeat instability in vivo. Cell Res 18: 198-213.

12. Kashi Y, King DG (2006) Simple sequence repeats as advantageous mutators in evolution. Trends Genet 22: 253-259.

13. Usdin K (2008) The biological effects of simple tandem repeats: lessons from the repeat expansion diseases. Genome Res 18: 1011-1019.

14. Coenye T, Vandamme P (2005) Characterization of mononucleotide repeats in sequenced prokaryotic genomes. DNA Res 12: 221-233.

15. Dieringer D, Schlotterer C (2003) Two distinct modes of microsatellite mutation processes: evidence from the complete genomic sequences of nine species. Genome Res 13: 2242-2251.

16. Kelkar YD, Tyekucheva S, Chiaromonte F, Makova KD (2008) The genome-wide determinants of human and chimpanzee microsatellite evolution. Genome Res 18: 30-38.

17. Alam CM, Singh AK, Sharfuddin C, Ali S (2013) In silico analysis of simple and imperfect microsatellites in diverse tobamovirus genomes. Gene 530: 193-200.

18. Alam CM, Singh AK, Sharfuddin C, Ali S (2014a) Genome-wide scan for extraction and analysis of simple and imperfect microsatellites in diverse carlaviruses. Infection, Genetics and Evolution 21: 287-294.

19. Alam CM, Singh AK, Sharfuddin C, Ali S (2014b) Incidence, complexity and diversity of simple sequence repeats across potexvirus genomes. Gene 537: 189-196.

20. Alam CM, Singh AK, Sharfuddin C, Ali S (2014c) In- silico exploration of thirty alphavirus genomes for analysis of the simple sequence repeats. Meta Gene 2: 694-705.

21. Alam CM, Sharfuddin C, Ali S (2015) Analysis of simple and imperfect microsatellites in Ebolavirus species and other genomes of Filoviridae family. Gene Cell and Tissue 2: e26204.

22. Singh AK, Alam CM, Sharfuddin C, Ali S (2014) Frequency and distribution of simple and compound microsatellites in forty-eight Human Papillomavirus (HPV) genomes. Infection, Genetics and Evolution 24: 92-98.

23. Mudunuri SB, Nagarajaram HA (2007) IMEx: imperfect microsatellite extractor. Bioinformatics 23: 1181-1187.

24. Li Y, Korol AB, Fahima T, Nevo E (2004) Microsatellites Within Genes: Structure, Function, and Evolution. Mol Biol Evol 21: 991-1007.

25. Tóth G, Gáspári Z, Jurka J (2000) Microsatellites in different eukaryotic genomes: survey and analysis. Genome Res 10: 967-981.

26. Deback C, Boutolleau D, Depienne C, Luyt CE, Bonnafous P et al. (2009) Utilization of microsatellite polymorphism for differentiating herpes simplex virus type 1 strains. J Clin Microbiol 47: 33-540. 